US Army Corps

of Engineers ${ }_{\circledast}$

Engineer Research and

Development Center

\title{
Identifying Degradation Products Responsible for Increased Toxicity of UV-Degraded Insensitive Munitions
}

Lee C. Moores, Alan J. Kennedy, Lauren May,

Shinita M. Jordan, Anthony J. Bednar, Stacy J. Jones,

David L. Henderson, Luke Gurtowski, and Kurt A. Gust 
The U.S. Army Engineer Research and Development Center (ERDC) solves the nation's toughest engineering and environmental challenges. ERDC develops innovative solutions in civil and military engineering, geospatial sciences, water resources, and environmental sciences for the Army, the Department of Defense, civilian agencies, and our nation's public good. Find out more at www.erdc.usace.army.mil.

To search for other technical reports published by ERDC, visit the ERDC online library at https://erdclibrary.on.worldcat.org/discovery. 


\section{Identifying Degradation Products Responsible for Increased Toxicity of UV-Degraded Insensitive Munitions}

Lee C. Moores, Alan J. Kennedy, Lauren May, Shinita M. Jordan, Anthony J. Bednar, Stacy J. Jones, David L. Henderson, Luke Gurtowski, and Kurt A. Gust

Environmental Laboratory

U.S. Army Engineer Research and Development Center 3909 Halls Ferry Road

Vicksburg, MS 39180

Stacy J. Jones

HX5

212 Eglin Parkway SE

Ft. Walton Beach, FL 32548

Final report

Approved for public release; distribution is unlimited.

Prepared for U.S. Army Corps of Engineers

Washington, DC 20314

Under USACE Environmental Quality and Installations Program 


\section{Preface}

This project was supported by the U.S. Army Corps of Engineers (USACE) under the Environmental Quality and Installations Program at the U.S. Army Engineer Research and Development Center.

The work was performed by the Army's Engineer Research and Development Center, Environmental Laboratory (ERDC-EL). At the time of publication of this paper, the Deputy Director of ERDC-EL was Dr. Brandon Lafferty and the Director was Dr. Edmund J. Russo Jr.

This article was originally published online in the journal Chemosphere on 24 September 2019.

The Commander of ERDC was COL Teresa A. Schlosser and the Director was Dr. David W. Pittman.

DISCLAIMER: The contents of this report are not to be used for advertising, publication, or promotional purposes. Citation of trade names does not constitute an official endorsement or approval of the use of such commercial products. All product names and trademarks cited are the property of their respective owners. The findings of this report are not to be construed as an official Department of the Army position unless so designated by other authorized documents. 


\title{
Identifying degradation products responsible for increased toxicity of UV-Degraded insensitive munitions
}

\begin{abstract}
A B S T R A C T
Degradation of insensitive munitions (IMs) by ultraviolet (UV) light has become a topic of concern following observations that some UV-degradation products have increased toxicity relative to parent compounds in aquatic organisms. The present investigation focused on the Army's IM formulation, IMX101, which is composed of three IM constituents: 2,4-dinitroanisole (DNAN), 3-nitro-1,2,4-triazol-5-one (NTO), and nitroguanidine (NQ). The IM constituents and IMX-101 were irradiated in a UV photo-reactor and then administered to Daphnia pulex in acute $(48 \mathrm{~h})$ exposures comparing toxicities relative to the parent materials. UV-degradation of DNAN had little effect on mortality whereas mortality for UVdegraded NTO and NQ (and associated degradation products) increased by factors of 40.3 and 1240 , respectively, making UV-degraded NQ the principle driver of toxicity when IMX-101 is UV-degraded. Toxicity investigations for specific products formed during UV-degradation of NQ confirmed greater toxicity than the parent NQ for degradation products including guanidine, nitrite, ammonia, nitrosoguanidine, and cyanide. Summation of the individual toxic units for the complete set of individually measured UV-degradation products identified for NQ only accounted for $25 \%$ of the overall toxicity measured in the exposures to the UV-degraded NQ product mixture. From these toxic unit calculations, nitrite followed by $\mathrm{CN}^{-}$were the principal degradation products contributing to toxicity. Given the underestimation of toxicity using the sum toxic units for the individually measured UV-degradation products of NQ we conclude that: (1) other unidentified NQ degradation products contributed principally to toxicity and/or (2) synergistic toxicological interactions occurred among the NQ degradation product mixture that exacerbated toxicity.
\end{abstract}

\section{Introduction}

As production of insensitive munitions (IMs) continues to expand, there is a need to understand how environmental processes affect the fate and effects of IMs during production and use. Given that IMs provide greater safety to soldiers due to reduction in unintended detonations, IMs are being pursued as a replacement for legacy munition compounds, such as trinitrotoluene (TNT). One of the Army's insensitive munitions, IMX-101, consists of a mixture of 2-4 dinitroanisole (DNAN), nitrotriazolone (NTO), and nitroguanidine (NQ) and is being increasingly deployed as a 
replacement for conventional munitions across weapons platforms (Lee et al. 2010; Williams et al., 2014). While the NQ parent compound is less toxic than TNT, RDX, DNAN and NTO in aquatic exposures (Gong et al., 2018; Gust et al., 2018; Gust et al., 2014; Gust et al., 2011; Lotufo et al., 2018; Stanley et al., 2015; Warner et al., 2012), the UV-degradation of NQ can generate products with higher toxic potency than the UV-degradation products of the other munitions constituents and nearly equal to those of TNT (Kennedy et al., 2015; Kennedy et al., 2017; Gust et al., 2017).

Nitroguanidine and NTO are much more water soluble than the munitions they are expected to replace; coupled with their low adsorption affinity to soils, these compounds are likely to be more mobile in waters than TNT (Taylor et al., 2015a). Whether the introduction of IMs to aquatic environments is due to permitted discharges from manufacturing facilities (Ribeiro et al., 2012; Li et al., 2013) or live fire use on training ranges (Taylor et al., 2015b), more information on IM fate and ecotoxicity is warranted. Aqueous NQ has been found to UV-degrade into a number of small nitrogenous compounds including nitrite, nitrate, ammonia, hydroxylamine, cyanamide, cyanoguanidine, urea, guanidine, hydroxyguanidine, and melamine (Burrows et al., 1988; Spanggord et al., 1987; Noss and Chyreck, 1984; Haag et al., 1990). This degradation was rapid, with a half-life of 0.6 days when irradiated by natural sunlight in the summer months. DNAN was found to generate methoxy nitrophenols and nitrite/nitrate, and dinitrophenol and presumably methanol during UV-degradation (Rao et al., 2013; Halasz et al., 2018; Taylor et al., 2017). To date, little information regarding the UV-degradation of NTO has been published (Le Campion et al., 1999), whereas a greater number of studies have focused on biodegradation pathways for this compound (Krzmarzick et al., 2015; Le Campion et al., 1998; Le Campion et al., 1998). Overall, each constituent of IMX-101 has been observed to be susceptible to UV-degradation, thus we sought to determine the impacts of these degradation products on toxicity.

Nitroguanidine was found to have a marked increase in toxicity after exposure to ultraviolet light, $2-3$ orders of magnitude in certain circumstances (Kennedy et al., 2017; Gust et al., 2017; van der Schalie, 1985), and represents a principle concern regarding the environmental risk of IMX-101 effluents that are either treated by UV-light (Felt, et al., 2013; Perreault et al., 2013) or are exposed to natural sunlight. Uncertainties associated with UV-degraded NQ have been a challenge for IMX-101 release permitting under the Clean Water Act, National Pollution Discharge and Elimination System (40CFR 122.44d). With the growing body of literature describing this increased toxicity of the undefined UV-degradation products of $\mathrm{NQ}$, we set forth to determine if the toxicity of the product mixture could be explained by previously reported NQ degradation compounds (e.g., ammonia, nitrite, guanidine, etc.) in addition to other degradation-product chemicals detected in the present study. Within the larger scope, the objectives of this investigation were to: (1) contrast parent material toxicity versus UV-degraded IM toxicity for all IMX-101 constituents including DNAN, NTO, and NQ as well as the IMX-101 formulation using standard acute toxicity assessments in Daphnia pulex (US EPA 2002); (2) determine and quantify the UV-degradation products, specifically for NQ; and (3) characterize the relative toxicity for all individual UV-degradation products identified for NQ to determine the primary source(s) of toxicity within the UV-degraded NQ product mixture.

\section{Materials and methods}

\subsection{Materials}

Military grade NTO ( $>95 \%$ pure), and the IM formulation IMX-
101 were obtained from the Holston Army Ammunition Plant (BAE Systems, Holston Army Ammunition Plant, TN) and used without further purification. Nitroguanidine, (NQ; $25 \%$ hydrated to stabilize), 2,4-dinitroanisole (DNAN), cyanamide, cyanoguanidine, nitrite, nitrate, guanidine hydrochloride, ethyl acetate, pyridine, FerroZine $^{\mathrm{TM}}$ (97\%) and zinc dust were purchased from Sigma Aldrich (St. Louis, MO). Potassium cyanide was purchased from Hach (Loveland, CO), and ammonium chloride, methanesulfonic acid was purchased from Fisher (Waltham, MA). Chloramine T (98\%) and barbituric acid were purchased from Spectrum (New Brunswick, NJ). All chemicals were $>99 \%$ purity unless otherwise stated and used as received. Nitrosoguanidine (GuNO, 11\% pure) was synthesized from literature procedures (Davis and Rosenquist, 1937) where specific methods are provided in the Supplemental Materials. All chemical solutions were made using high-purity water $(>18.2 \mathrm{M} \Omega$ ) produced using a Gemini High Purity Water Filtration system (Aries Filter Works, Berlin, NJ).

\subsection{UV-degradation}

UV-Degradation was conducted using solutions of the parent compounds for both toxicity exposures and degradation product analysis. For product identification studies, solutions of nominally $0.96 \mathrm{mM}$ (NQ, $100 \mathrm{mg} / \mathrm{L}$ ), $0.58 \mathrm{mM}$ (DNAN, $115 \mathrm{mg} / \mathrm{L}$ ), and $0.08 \mathrm{mM}$ (NTO, $10.4 \mathrm{mg} / \mathrm{L}$ ) were prepared in high purity water and $5 \mathrm{~mL}$ added to each of 6 quartz test tubes (Technical Glass, Painesville Twp., OH, $1.18 \mathrm{~cm}$ ID) and $100 \mathrm{~mL}$ of DNAN solution was added to a quartz beaker (Technical Glass, $3.2 \mathrm{~cm}$ ID) capped with a rubber stopper. The tubes were arranged in the outer ring of the carousel inside a Rayonet photoreactor (Model RPR-100, Southern New England Ultraviolet Co. Branford, CT) equipped with sixteen, $300 \mathrm{~nm}$ lightbulbs (RPR-3000A, Southern New England Ultraviolet Co.). Irradiation times were carefully controlled with a timer controller (Control Co. Webster, TX), and photon flux measured to be $1.38 \pm 0.16 \times 10^{-8} \mathrm{E}$ per second by ferrioxalate actinometry (Goldstein and Rabani, 2008) where the formation of ferrous iron was monitored by UV-vis spectroscopy (Cary 8454, Agilent, Santa Clara, CA) after chelation with FerroZine ${ }^{\mathrm{TM}}$.

The UV-degradation of IMs for toxicity assessments were performed as we previously described in Kennedy et al. (2017). Briefly, solutions of nominally $100 \mathrm{mg} / \mathrm{L} \mathrm{NQ} 121 \mathrm{mg} / \mathrm{L} \mathrm{NTO}, 100 \mathrm{mg} / \mathrm{L}$ DNAN and $100 \mathrm{mg} / \mathrm{L}$ IMX-101 were prepared in $220 \mu \mathrm{S} \mathrm{cm}^{-1}$ and $100 \mathrm{~mL}$ was added to each of 10 quartz beakers (Technical Glass, $3.2 \mathrm{~cm}$ ID) inside the previously described photo-reactor for $4 \mathrm{~h}$. The beakers were arranged in a custom made carousel holder (to accommodate larger volumes required for bioassays) along the outer ring. UVdegradation solutions were mixed well prior to determination of degradation by high performance liquid chromatography (HPLC, Agilent 1200 series, Agilent Technologies Santa Clara, CA), and transported in $1 \mathrm{~L}$ amber bottles to the toxicity lab to avoid further UV-degradation.

\subsection{Analytical}

Degradation for all IMs were measured using HPLC (Agilent 1200 series, Santa Clara, CA Bruker Hystar software Billerica, MA) using a $\mathrm{C}_{18}$ column (Phenomenex, Synergi ${ }^{\mathrm{TM}} 4 \mu \mathrm{m}$ Hydro-RP $80 \AA$ liquid chromatography column (LC), $250 \times 4.6 \mathrm{~mm}$, Torrance, CA) at a flow rate of $1.1 \mathrm{~mL} / \mathrm{min}$, a column temperature of $25^{\circ} \mathrm{C}$, and diode array detection (Russell et al., 2014). NQ was analyzed using a $100 \%$ water mobile phase, NTO was analyzed using a $0.005 \%$ aqueous trifluoroacetic acid mobile phase, and DNAN was analyzed using an isocratic mobile phase of $40 \%$ methanol in water. Ammonia and guanidine were analyzed by ion chromatography (Dionex ICS5000, Sunnyvale, CA), with a CS16 analytical column and a 
conductivity detector, using an isocratic mobile phase of $30 \mathrm{mM}$ methanesulfonic acid in high-purity water flowing at a rate of $0.6 \mathrm{~mL} / \mathrm{min}$.

Cyanide was detected on a Lachat QuikChem Flow Injection Analysis System (Hach, Model QC8500 Series II, Loveland, CO) with high purity water as the carrier using the following aqueous solutions: $1 \mathrm{M}$ sodium dihydrogen phosphate with $\mathrm{pH}$ adjusted to 8 with $1 \mathrm{M} \mathrm{NaOH}, 4 \mathrm{~g} / \mathrm{L}$ chloramine $\mathrm{T}$, and a color reagent consisting of $15.0 \mathrm{~g}$ barbituric acid, $75 \mathrm{~mL}$ pyriadine, and $15 \mathrm{~mL}$ concentrated hydrochloric acid $(12 \mathrm{M} \mathrm{HCl})$ diluted to a volume of $1 \mathrm{~L}$. Samples were distilled by using either a Lachat microdist or minidist system (Hach, Loveland, CO) prior to analysis to remove interfering compounds. Samples generated via NQ UV-degradation had $0.024 \mathrm{~g}$ of sulfamic acid added to each $6 \mathrm{~mL}$ sample prior to the distillation to avoid nitrite and nitrate interferences.

Products of DNAN UV-degradation were identified by gas chromatography mass spectrometry (GC-MS) using an Hewlett Packard 6890 Series (Agilent, Santa Clara, CA), GC and Hewlett Packard 5973 MS following modifications of USEPA method 8270D (1998) and matching to the NIST spectral library (NIST v17, Software v2.3 Gaithersburg, MD). The UV-degraded mixture $(30 \mathrm{~mL})$ was acidified to facilitate liquid-liquid extraction into ethyl acetate $(3 \times 25 \mathrm{~mL})$, and the combined organic layers concentrated by rotary evaporation.

\subsection{Aquatic hazard testing}

Acute (48-h) toxicity bioassays were conducted for each test chemical using to a standard method (U.S. EPA 2002) relevant to the National Pollutant Discharge Elimination System, enforced by the Clean Water Act. Daphnia pulex was selected because it is a standard freshwater ecotoxicological model, has shown greater sensitivity to some chemicals relative to a conspecific (D. magna), and was more sensitive to DNAN than Ceriodaphnia dubia (Kennedy et al., 2015), yet has no literature reported for UV-degraded IM toxicity. The source of the D. pulex was A. Beckerman (University of Sheffield, UK), a previously sequenced genotype (Kennedy et al., 2015) that is particularly well studied in genomics investigations of ecotoxicological effects (Eads et al., 2008) and can be considered a human health model due to a large number of shared genes (Colbourne et al., 2011).

Briefly, acute toxicity bioassays were conducted at $25 \pm 1^{\circ} \mathrm{C}$ using a 16L:8D photoperiod (wide spectrum florescent light, no UV) in environmentally controlled chambers (Darwin Chambers Company, St. Louis, MO, USA). The parent (undegraded) compounds: IMX-101 (348 mg/L, measured), NQ (1,619 mg/L, measured), NTO (1,507 mg/L, measured) and DNAN ( $120 \mathrm{mg} / \mathrm{L}$, measured) were used in bioassay exposures at relatively high concentrations that were selected specifically to induce a toxicological effect for comparison to the UV-degraded IMs toxicity. For each assessment, the parent IMs, UV-degraded IMs, and five individual UV-degradation products identified in the UV-degraded NQ product mixture included 5 to 8 exposure concentrations generated from a $50 \%$ dilution series (Supplemental Table S1), using a standard reconstituted water formulated according to US EPA (2002) and diluted to $220 \mu \mathrm{S} / \mathrm{cm}$, which was found optimal for D. pulex (Laird et al., 2015). This water was used as the diluent and the control. Each exposure concentration consisted of eight replicate $40 \mathrm{~mL}$ glass scintillation vials, each containing 5 organisms. The individual nominal exposure concentrations tested are provided for each compound in the supporting information (Supplemental Table S1). Water quality parameters (temperature, $\mathrm{pH}$, dissolved oxygen, conductivity) were measured at test termination and water samples were collected at test initiation and termination for analytical determination of the chemical exposures. Toxicological endpoints were generated from measured concentrations summarized by arithmetic means (if the concentration changed $<20 \%$ from test initiation to termination) or geometric means (if concentration changed $>20 \%$ from test initiation to termination), as described in OECD methods (OECD, 2012). The test endpoint assessed was survival following 48-h exposure. Median Lethal Concentrations (LC50) and partial lethal concentrations (e.g., LC10) were calculated using ToxCalc (Tidepool Scientific, McKinleyville, CA) using the trimmed Spearman Karber Method. No effect concentrations were calculated using U.S. EPA BenchMark Dose Software (BMDS) (v2.7; US Environmental Protection Agency, 2018).

To infer information on individual IM constituent contribution to IMX-101 mixture toxicity, as well as contribution of NQ degradation products to the UV-degraded NQ toxicity, toxic units (TUs) were determined as the quotient of the measured parent compound concentration and the LC50 of each constituent, as previously described (Han et al., 2006). All concentrations were based on the original parent compound concentration so that a relative UVdegraded-to-parent compound comparisons in toxicity could be determined as well as the relative contribution to the UV-degraded product to the IMX-101 mixture formulation.

\section{Results and discussion}

\subsection{Comparative toxicity of parent versus UV-Degraded IMX-101 and constituents}

UV-degradation of IMX-101 caused an approximately 1 order of magnitude increase in toxic potency, decreasing the $48 \mathrm{~h} \mathrm{LC50}$ from $62.5 \mathrm{mg} / \mathrm{L}$ to $4.65 \mathrm{mg} / \mathrm{L}$ (Table 1, Supplemental Fig. S1). Comparative evaluation of parent versus UV-degraded IM constituents that make up the IMX-101 mixture indicated significant increases in toxicity for NQ and NTO, but not DNAN (Table 1, Supplemental Fig. S1). The most dramatic increase in toxicity was a $>3$ order of magnitude increase in toxicity for NQ when $90 \%$ of the parent compound had been degraded, leading to a decrease in the LC50 from $1,485 \mathrm{mg} / \mathrm{L}$ to $1.2 \mathrm{mg} / \mathrm{L}$. Even relatively minor degradation of NQ (7\% of parent NQ degraded) lead to a nearly 2 order of magnitude increase in toxicity (Table 1). UV-degradation of NTO caused a 3.7-fold increase in toxicity, decreasing the LC50 of NTO from $113.6 \mathrm{mg} / \mathrm{L}$ to $30.5 \mathrm{mg} / \mathrm{L}$ in non-pH adjusted exposures (Table 1). The increases in NQ and NTO toxicity when UV-degraded are consistent with previous results with another cladoceran, C. dubia (Kennedy et al., 2017).

Data sets for $D$. pulex (generated in the present study) and C. dubia (Kennedy et al., 2017) were investigated utilizing a toxic units approach to provide insight into the relative contribution of each constituent of IMX-101 to overall toxicity before and after UVdegradation (Fig. 1). Prior to UV-degradation, DNAN was the most toxic constituent within the IMX-101 mixture formulation, whereas after UV-degradation, the toxicity of IMX-101 increased in both $D$. pulex and C. dubia where the toxic units indicated UV-degraded NQ was the principle driver of toxicity (Fig. 1). The similarity between the toxic responses between the two species support the observation that toxicological responses are conserved and consistent between cladoceran species. Although increased toxicity of UV-degraded NQ is pervasive across species (Kennedy et al., 2017; Gust et al., 2017; van der Schalie, 1985), the >3 order of magnitude increase observed in the D. pulex exposed to the $90 \%$ UV-degraded NQ (Supplemental Fig. S1) is the greatest increase in toxicity associated with UV-degraded IMs reported in the published literature to date. 
Table 1

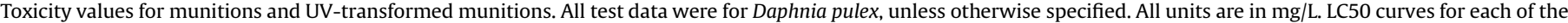
tested munitions and the concentrations used for each exposure can be found in Supplemental Fig. S1 and Supplemental Table S1).

\begin{tabular}{|c|c|c|c|}
\hline munition & LC50 & LC10 & reference \\
\hline TNT & $\begin{array}{l}5.1(1.5-17.9)^{\mathrm{A}} \\
4.0(3.7-4.5)^{\mathrm{A}}\end{array}$ & - & $\begin{array}{l}\text { Johnson et al. (1994) } \\
\text { Burton et al., } 1993\end{array}$ \\
\hline IMX-101 & $62.5(52.3-72.4)$ & $35.6(24.0-44.2)$ & this study \\
\hline DNAN & $25.2(20.1-30.0)$ & $12.28(7.5-16.2)$ & this study \\
\hline NTO (neutralized pH) & $1234.8(1040.7-1463.6)$ & $718.6(445.8-888.3)$ & this study \\
\hline $\mathrm{NTO}(\mathrm{pH} \approx 2.7)$ & $113.6(111.4-115.9)$ & - & this study \\
\hline NQ & $1485.7(999.1-3220.2)$ & $318.6(197.3-433.9)$ & this study \\
\hline TNT UV-degradation products & $1.0(0.6-1.7)$ & - & Johnson et al. (1994) \\
\hline IMX-101 UV-degradation products & $4.7(4.1-5.3)$ & $2.8(2.2-3.3)$ & this study \\
\hline DNAN UV-degradation products & $27.6(25.0-30.6)$ & NA & this study \\
\hline NTO UV-degradation products & $30.5(27.5-34.2)$ & $22.1(18.2-24.9)$ & this study \\
\hline NQ UV-degradation products (90\% degraded) & $1.2(0.4-2.3)$ & $0.4(0.0-0.8)$ & this study \\
\hline NQ UV-degradation products (7\% degraded) & $17.4(15.2-19.9)$ & $4.4(0.1-10.1)$ & this study \\
\hline
\end{tabular}

A for Daphnia magna.

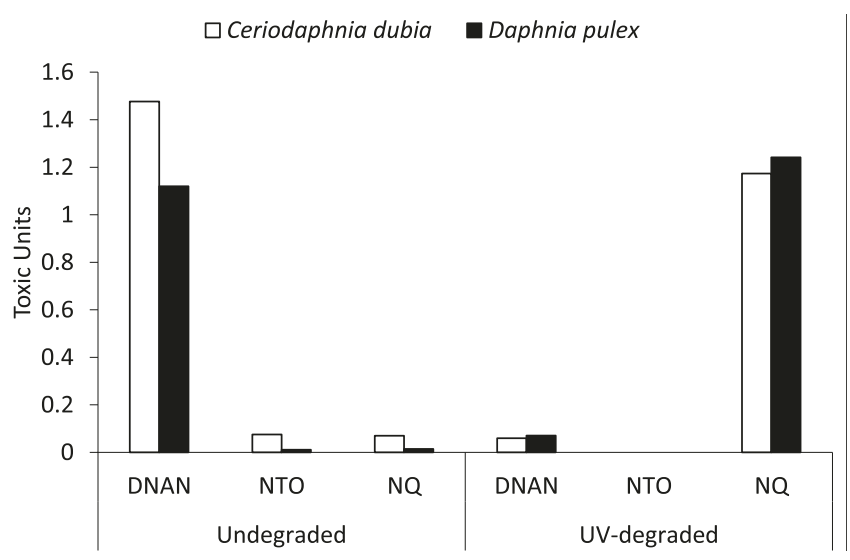

Fig. 1. Toxic units of individual IM constituents for two cladoceran species, D. pulex and C. dubia, before and after the IMs were subjected to UV-irradiation. Data for C. dubia is derived from Kennedy et al. (2017).

\subsection{Kinetics of UV-Degradation for each IMX-101 constituent}

In parallel to the acute toxicity assays described above, the UVdegradation rates were determined for each of the IM-101 constituents (Supplemental Fig. S2). For DNAN and NQ the degradation kinetics were best described by $0^{\text {th }}$ order reactions with rate constants of $0.0032 \mathrm{M} \mathrm{h}^{-1}$ and $0.0397 \mathrm{M} \mathrm{min}^{-1}$, respectively. For NTO, the concentration was sufficiently low for the UV-degradation to be modeled as a pseudo-first order reaction with a rate constant of $0.015 \mathrm{~min}^{-1}$. The different starting concentrations (i.e., optical density) hindered the ability to make direct comparisons of the rate constants, but relative comparisons of the concentrations tested indicated the trend of $k_{N Q}>k_{D N A N}$, which corresponds with previous observations (Moores et al., 2019; Halasz et al., 2018).

\subsection{Identification of UV-Degradation products for DNAN and NTO}

UV-degradation of DNAN resulted in the formation of nitrite (Supplemental Fig. S3), nitrate (Supplemental Figs. S4 and S5), dinitrophenol (Supplemental Fig. S6) and both isomeric methoxynitrophenols (Supplemental Fig. S7), in agreement with previous observations (Rao et al., 2013; Halasz et al., 2018; Taylor et al., 2017). A number of other products were observed as products of UVdegradation for DNAN which could not be unequivocally identified, and their spectra and discussion can be found in the Supplemental Materials (Supplemental Figs. S8-S11). Formation of nitrite
(Supplemental Fig. S12) and nitrate (Supplemental Fig. S13) was observed during the UV-degradation of NTO, and presumably the corresponding hydroxylated triazolone or its tautomer, urazole (Le Campion et al., 1998). During these initial UV-degradation product identification experiments, a greater focus was made on identifying the products of NQ since there is now abundant evidence that these UV-degradation products are the most important for determining the increased toxicity of the UV-degraded IMX-101 formulation.

\subsection{Identification of UV-Degradation products for $N Q$}

We first identified UV-degradation products for NQ from literature observations (Noss and Chyreck, 1984; Spanggord et al., 1987; Burrows et al., 1988) and empirically measured product formation in NQ UV-degradation kinetics experiments (Fig. 2). The results indicated that nitrate + nitrite formed the most rapidly followed by guanidine. Only trace amounts of ammonium and cyanoguanidine were formed after $>40 \%$ degradation of the parent NQ. Previously, formation of the monomer of cyanoguanidine, cyanamide, and its trimer, melamine has been demonstrated (Noss and Chyreck, 1984; Spanggord et al., 1987; Burrows et al., 1988). The HPLC chromatograms in Fig. 3 show the overlay of cyanoguanidine and a sample of NQ before and after UV-degradation demonstrating the growth of poorly resolved peaks with retention times of $1.5-2.5 \mathrm{~min}$, which are likely ionic constituents and guanidine eluting with the injection peak, a peak with a retention time of 2.9 min that could not be identified in the initial screening, and a peak with a retention time of $3.6 \mathrm{~min}$ which corresponds to cyanoguanidine formation. The ratio of the integrations for cyanoguanidine using wavelengths of $216 \mathrm{~nm}$ and $230 \mathrm{~nm}$ is 3.82 compared to the integration ratio of 3.81 for the NQ UV-degradation product, each at the same retention time. The similarities in the cyanoguanidine and NQ UVdegradation product retention times and integration ratios gives good evidence that the identification of the degradation product observed in the present study is cyanoguanidine. Retention times found for cyanamide was very similar to cyanoguanidine, but had 216/230 ratios of 0.26 . Melamine eluted later than cyanamide and cyanoguanidine, but did not have a corresponding peak in the NQ UV-degradation chromatograms. Summing the products in Fig. 2 accounted for $65.6 \%$ and $76.7 \%$ of carbon and nitrogen, respectively, on a molar basis.

\subsection{Toxicity screening of previously identified NQ UV-Degradation compounds}

Toxicity results for the five NQ UV-degradation products 


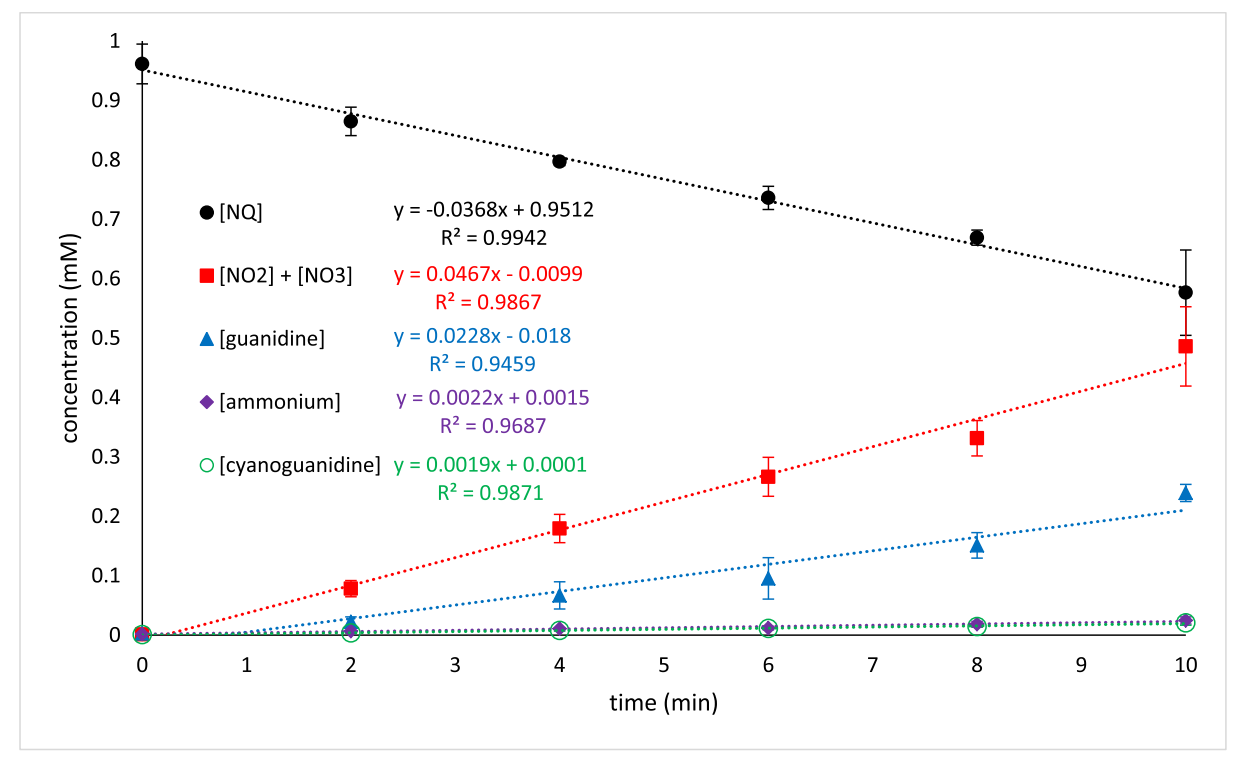

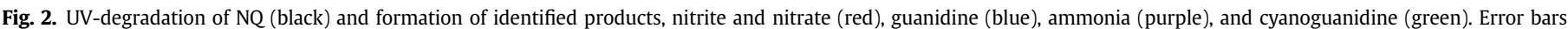

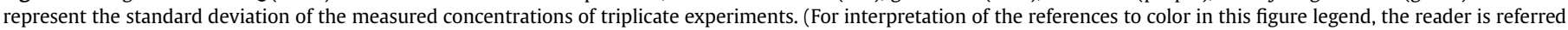
to the Web version of this article.)

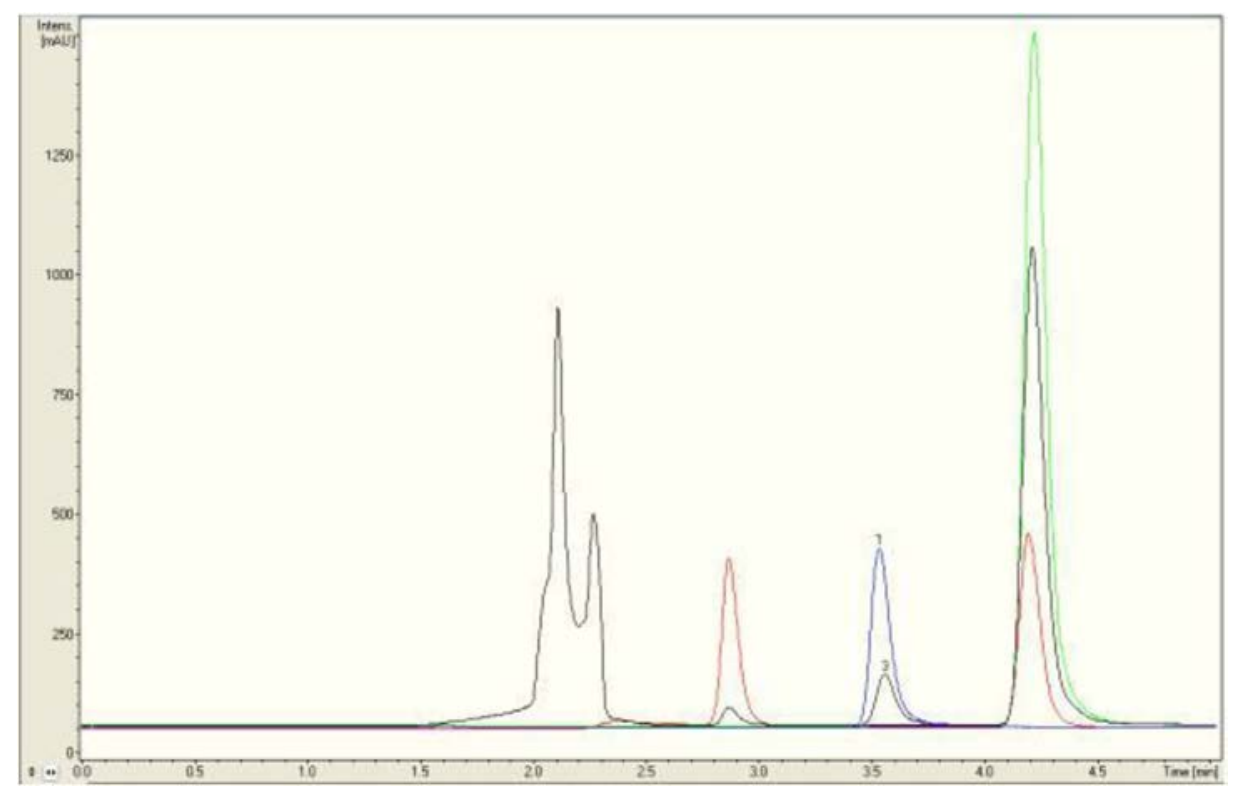

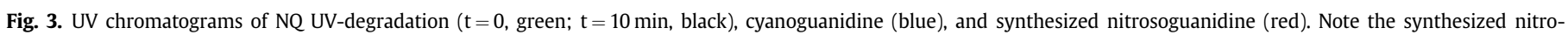
soguanidine contains the starting material, NQ. (For interpretation of the references to color in this figure legend, the reader is referred to the Web version of this article.)

identified in the literature (Gersich and Hopkins, 1986; Xiang et al., 2010; Scott and Crunkilton, 2000) and further confirmed using analytical chemistry in the present study were determined. We used a combination of literature values for $D$. pulex as well as generation of new toxicity data for previously untested chemicals to provide context for the sum toxicity of UV-degraded NQ (Table 2). Cyanamide and its oligomers, cyanoguanidine (detected here) and melamine, did not elicit a toxic response by $D$. pulex, thus no analytical confirmations were conducted for these tests. Of these products found in the initial screening, guanidine was the most toxic with an LC50 of $14.2 \mathrm{mg} / \mathrm{L}$. Although relatively toxic, the presence of guanidine in the UV-degraded NQ product mixture was relatively low $(\sim 1.0 \mathrm{mg} / \mathrm{L})$ after the $1: 100$ sample dilution (Table 2 ,
Column 7) that was required to eliminate $100 \%$ mortality of $D$. pulex in the highly-potent $90 \%$ UV-degradation product of the $100 \mathrm{mg} / \mathrm{L}$ NQ solution (Supplemental Fig. S1). In fact, after accounting for all of the initially screened UV-degradation products, the toxicity of the NQ UV-degradation product mixture could not be explained. Therefore, we sought to determine if additional, presently unidentified UV-degradation products were present, and if present, the contribution of each to toxicity in D. pulex.

\subsection{Further NQ UV-Degradation product identification and toxicity assessments}

A more rigorous investigation of the UV-degradation chemistry 
Table 2

Toxicity values for individual NQ UV-degradation products. All test data were for Daphnia pulex, unless otherwise specified. All concentrations have the units mg/L.

\begin{tabular}{|c|c|c|c|c|c|c|}
\hline \multirow[t]{2}{*}{ chemical } & \multirow[t]{2}{*}{ LC50 } & \multirow[t]{2}{*}{ reference } & \multicolumn{2}{|l|}{$7 \%$ degraded } & \multicolumn{2}{|l|}{$90 \%$ degraded } \\
\hline & & & conc. in product mixture ${ }^{\mathrm{e}}$ & conc. at $\mathrm{LC} 50^{\mathrm{f}}$ & conc. in product mixture ${ }^{\mathrm{e}}$ & conc. at $\mathrm{LC} 50^{\mathrm{f}}$ \\
\hline \multicolumn{7}{|c|}{ previously identified products } \\
\hline ammonia- $\mathrm{N}^{\mathrm{a}}$ & $26.25(24.11-28.75)^{b}$ & ich and Hopkins, 1986 & 0.256 & 0.045 & 2.66 & 0.0313 \\
\hline \multirow[t]{2}{*}{ nitrite-N } & $18.72(14.7-30.51)^{c}$ & Xiang et al., 2010 & & & & \\
\hline & $28.78(24.58-35.13)^{c}$ & Xiang et al., 2010 & & & & \\
\hline \multirow[t]{3}{*}{ nitrate-N } & $323(198-469)^{\mathrm{d}}$ & & & & & \\
\hline & $453(299-659)^{\mathrm{d}}$ & & & & & \\
\hline & $611(455-820)^{\mathrm{d}}$ & $\mathrm{t}$ and Crunkilton, & $4.69^{g}$ & $0.814^{\mathrm{g}}$ & $135^{\mathrm{g}}$ & $1.59^{g}$ \\
\hline guanidine & $14.2(12.4-16.2)$ & this study & 3.23 & 0.562 & 84.8 & 1.00 \\
\hline cyanoguanidine & $>100$ (nominal) & this study & 1.15 & 1.990 & 10.8 & 0.128 \\
\hline cyanamide & $>100$ (nominal) & this study & $\mathrm{N} / \mathrm{A}$ & & $\mathrm{N} / \mathrm{A}$ & \\
\hline melamine & $>100$ (nominal) & this study & $\mathrm{N} / \mathrm{A}$ & & $\mathrm{N} / \mathrm{A}$ & \\
\hline \multicolumn{7}{|c|}{ Newly Identified Products } \\
\hline \multirow{4}{*}{$\begin{array}{l}\text { Nitrosoguanidine } \\
\text { cyanide }\end{array}$} & $>11(\text { nominal })^{\mathrm{h}}$ & this study & $\mathrm{N} / \mathrm{A}$ & & $\mathrm{N} / \mathrm{A}$ & \\
\hline & $0.09(0.07-0.10)$ & & & & & \\
\hline & $0.13(0.11-0.16)$ & this study & 0.07 & 0.012 & 0.35 & 0.0041 \\
\hline & $0.17(0.15-0.20)$ & & & & & \\
\hline \multicolumn{7}{|c|}{ a presented as total ammonia-N for units consistency, albeit unionized ammonia is more predictive of toxicity. } \\
\hline \multicolumn{7}{|c|}{ b Back calculated from unionized ammonia LC50 of $2.94(2.7-3.22)$ using pH 8.5 and temperature of $20^{\circ} \mathrm{C}(11.2 \%$ unionized). } \\
\hline \multicolumn{7}{|c|}{ c For Daphnia similoids. } \\
\hline \multicolumn{7}{|c|}{ d For Daphinia magna. } \\
\hline \multicolumn{7}{|c|}{ e Concentrations calculated from rates of formation. } \\
\hline \multicolumn{7}{|c|}{ f Concentrations calculated by accounting for dilution of $100 \mathrm{ppm}$ starting concentration to the determined LC50 for UV-degraded NQ ( $17.36 \mathrm{ppm}$ and $1.18 \mathrm{ppm}$ for the $7 \%$} \\
\hline \multicolumn{7}{|c|}{ nd $>90 \%$ degraded experiments, respectively) to estimate the maximum exposure concentration. } \\
\hline \multicolumn{7}{|c|}{ g Expressed as the sum of nitrite and nitrate concentrations due to interconversion during UV-degradation experiments. } \\
\hline h D. pulex expos & an impure mixture of 1 & m GuNO and 89 ppm & & & & \\
\hline
\end{tabular}

of NQ was conducted and toxic responses to the degradation products assessed. First, nitrosoguanidine (GuNO) has been proposed to be a UV-degradation intermediate of NQ (Noss and Chyreck, 1984; Burrows et al., 1988). However, this had been refuted initially due to the finding that the $\mathrm{N}-\mathrm{NO}_{2}$ scission was homolytic (Pace and Holmes, 1983), and presumed to be the result of microbial reduction (Kaplan, et al., 1982). Investigation of the chromatogram's unidentified peak (Fig. $3, \mathrm{RT}=2.9 \mathrm{~min}$ ) corresponded well with the elution of GuNO in chromatograms from literature accounts (Burrows et al., 1984). Given no commercially available analytical standard for GuNO, we conducted synthesis of the chemical for analytical and toxicity bioassay use. HPLC analysis of the synthesized product showed poor purity of the synthetized GuNO (11\%, 89\% NQ), but sufficient overlap with the unidentified peak and nearly identical $254 \mathrm{~nm} / 300 \mathrm{~nm}$ integration ratios of 21.1 and 21.2 for the synthesized GuNO and UV-degraded NQ, respectively to provide reasonable certainty of its presence. The GuNO/NQ product mixture was utilized in an acute $D$. pulex toxicity test indicated that approximately $11 \mathrm{mg} / \mathrm{L} \mathrm{GuNO}+89 \mathrm{mg} / \mathrm{L} \mathrm{NQ}$ was not acutely toxic. It should be noted that more or less of the GuNO may have been present in the product mixture, as no analytical determinations against chemical standards were possible with the low purity synthesized GuNO. Overall, Nitroso compounds are typically regarded as hazardous materials due to their carcinogenic properties (Swann, 1975), which may be of lesser importance in an acute test in D. pulex; however, chronic exposure assessments and further fate studies of this product are warranted. Regarding the environmental relevance of GuNO formation, the greater photolytic rate compared to NQ (Burrows et al., 1988) suggests this product can only form when penetration depths are kept short (i.e., high optical density, large concentrations of NQ). It is not anticipated that this product would form in significant quantities under sunlight-driven UV-degradation of NQ in natural waters, but in might be a product of concern as a potential byproduct of wastewater treatment employing UV-degradation.

With the results from GuNO showing no acute toxicity at the concentration tested, further experimentation was undertaken to identify products that might explain the toxicity of the UVdegraded NQ product mixture. Preliminary colorimetric testing gave a positive result for cyanide; however, cyanamide, cyanoguanidine, melamine, nitrite and nitrate were all found to give false positive results. Upon distillation of solutions containing each individual product, only UV-degraded NQ product mixture and potassium cyanide were capable of being distilled. The formation of cyanide was determined analytically during the UV-degradation of NQ and its formation is shown in Fig. 4. To the authors' knowledge, this is the first time, cyanide was analytically confirmed to be a product of NQ UV-degradation. Although CN is highly toxic, the concentration in the UV-degraded product mixture was very low

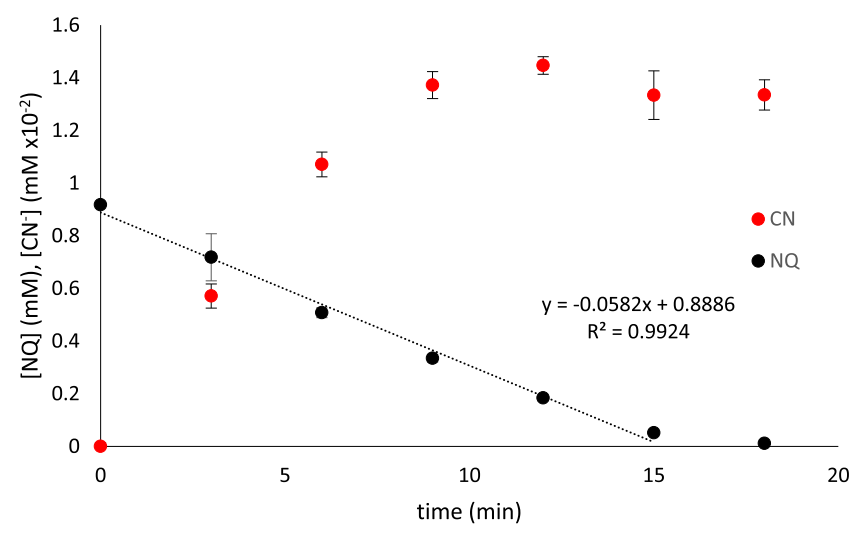

Fig. 4. Formation of cyanide (red) and NQ UV-degradation (black). Note the different units for cyanide and NQ concentrations. Error bars represent the standard deviation of the analytically determined concentrations of $\mathrm{NQ}$ and $\mathrm{CN}^{-}$at each sampling interval in triplicate experiments. \%RSD for each of the triplicate samples was $<1.0 \%$ for $\mathrm{CN}^{-}$. The trend line representing pseudo- $0^{\text {th }}$ order kinetics was observed through the sample at $12 \mathrm{~min}$, but deviated from linearity after this point as the solution became optically dilute where pseudo-1st order kinetics would best represent the UV-degradation. (For interpretation of the references to color in this figure legend, the reader is referred to the Web version of this article.) 

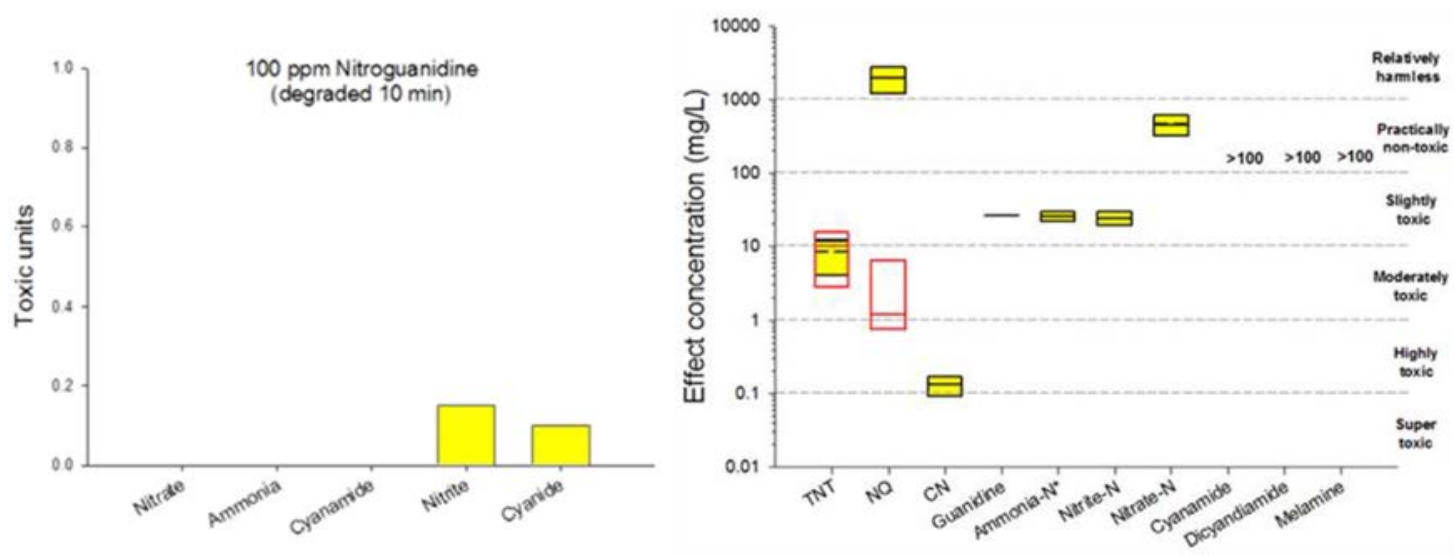

Fig. 5. Toxic units and relative toxicity of UV-degraded NQ solutions.

$(0.004 \mathrm{mg} / \mathrm{L})$ after the $1: 100$ dilution that was required to eliminate $100 \%$ mortality of $D$. pulex in the UV-degraded NQ product exposures (Table 1, Supplemental Fig. S1). Further investigation on the formation, stability and fate of the cyanide may be warranted, as there is an apparent decrease in concentration after NQ UVdegradation is complete. This could be due to the reaction of cyanide with hydroxyl radicals generated from the photolysis of nitrate/nitrite (Mack and Bolton, 1999), volatilization of HCN, or sorption by the septa used to deter HCN volatization during the UVdegradation experiments.

\section{Conclusions}

The toxicity of the UV-degraded IMX-101 mixture was confirmed to be in large part due to the degradation products of NQ. Many of the UV-degradation products found for NQ NTO and DNAN from previous work were confirmed by this study. Additionally, for the first time, cyanide was detected during UV-degradation of NQ. Among the analytically determined NQ UV-degradation products, cyanide was the most toxic, followed by guanidine, nitrite, and ammonia. However, individual concentrations of each of these products cannot fully account for the observed toxicity of the UVdegradation product mixture. Specifically, nitrite and CN contributed TUs of approximately 0.15 and 0.10 , respectively (Fig. 5), thus accounting for only $25 \%$ of the observed toxic response. Evaluation of nitrosoguanidine requires further testing with a pure material to provide a robust toxicity assessment, however our initial evaluation suggests that it is not formed in sufficient quantity and does not have high enough potency to explain the sum-balance of the observed toxicity of UV-degraded NQ. It is, therefore, hypothesized that the acute toxicity of the UV-degradation product mixture may be attributable to as yet to be identified degradation products or a toxicologically synergistic effect among degradation products. Additional efforts are required to better characterize the mixture toxicology among NQ UV-degradation products and to elucidate the mode(s) of action utilizing a toxicogenomics approach to understand the degree to which these products and interactions contribute to the observed toxic response. Finally, efforts to characterize the real-world scenarios of IMX-101 constituent UVdegradation and the toxicity of NQ UV-degradation by natural sunlight and the rate by which these processes occur is needed to determine the environmental implications of UV-induced NQ degradation on IMX-101 toxicity in nature.

\section{Acknowledgements}

The use of trade, product or firm names in this report is for descriptive purposes only and does not imply endorsement by the U.S. Government. The tests described and the resulting data presented herein were obtained from research conducted under the Environmental Quality and Technology Program of the United States Army Corps of Engineers by the USAERDC. Permission was granted by the Chief of Engineers and PEO AMMO to publish this information. The findings of this report are not to be construed as an official Department of the Army position unless so designated by other authorized documents.

\section{Appendix A. Supplementary data}

Supplementary data to this article can be found online at https://doi.org/10.1016/j.chemosphere.2019.124958.

\section{References}

Burrows, E.P., Brueggeman, E.E., Hoke, S.H., 1984. Chromatographic trace analysis of guanidine, substituted guanidines and s-triazines in water. J. Chromatogr. 294, 494-498.

Burrows, W.D., Schmidt, M.O., Chyrek, R.H., Noss, C.I., 1988. Photochemistry of Aqueous Nitroguanidine. U.S. Army Biomedical Research and Development Laboratory, Fort Detrick, MD, pp. 1-28. Technical Report ADA203200. Oct 1984Sep. 1986.

Burton, D.T., Turley, S.D., Peters, G.T., 1993. Toxicity of Nitroguanidine, Nitroglycerin, Hexahydro-1,3,5-trinitro-1,3,5-triazine (RDX), and 2,4,6-Trinitrotoluene (TNT) to Selected Freshwater Aquatic Organisms. U.S. Army Medical Research and Development Command, Fort Detrick, MD, pp. 1-261. Technical Report ADA267-467. November 1987-March 1991.

Colbourne, J.K., Pfrender, M.E., Gilbert, D., Thomas, W.K., Tucker, A., Oakley, T.H., 2011. The ecoresponsive genome of Daphnia pulex. Science 331, 555-561.

Davis, T.L., Rosenquist, E.N., 1937. Studies in the urea series. XV. Transformation of nitrosoguanidine. Alkylnitrosoguanidines. N-R,N'-R'-Dialkylguanidines. J. Am. Chem. Soc. 2112-2115.

Eads, B.D., Andrews, J., Colbourne, J.K., 2008. Ecological genomics in Daphnia: stress responses and environmental sex determination. Heredity 100, 184-190.

Environmental Protection Agency, 2018. Benchmark Dose tools, Ver2.7. Washington DC. Available from: https://www.epa.gov/bmds.

Felt, D., Johnson, J.L., Larson, S., Hubbard, B., Henry, K., Nestler, C., Ballard, J.H., 2013. Evaluation of treatment technologies for wastewater from insensitive munitions production: phase 1: Technology down-select. ERDC/EL TR-13-20. US Army Engineer Research and Development Center, Vicksburg, MS. https://apps. dtic.mil/dtic/tr/fulltext/u2/a592972.pdf.

Gersich, F.M., Hopkins, D.L., 1986. Site-specific acute and chronic toxicity of ammonia to Daphnia magna straus. Environ. Toxicol. Chem. 5, 443-447.

Goldstein, S., Rabani, J., 2008. The ferrioxalate and iodide-iodate actinometers in the UV region. J. Photochem. Photobiol., A 193, 50-55.

Gong, P., Donohue, K.B., Mayo, A.M., Wang, Y., Wilbanks, M.S., Barker, N.D., Guan, X, Gust, K.A., 2018. Comparative toxicogenomics of three insensitive munitions constituents 2,4-dinitroanisole, nitroguanidine and nitrotriazolone in the soil nematode Caenorhabditis elegans. BMC Syst. Biol. 12 (Suppl. 7), 92. https://doi. 
org/10.1186/s12918-018-0636-0.

Gust, K.A., Wilbanks, M.S., Guan, X., Pirooznia, M., Habib, T., Yoo, L., Wintz, H. Vulpe, C.D., Perkins, E.J., 2011. Investigations of transcript expression in fathead minnow (Pimephales promelas) brain tissue reveal toxicological impacts of RDX exposure. Aquat. Toxicol. 101 (1), 135-145

Gust, K.A., Najar, F.Z., Habib, T., Lotufo, G.R., Piggot, A.M., Fouke, B.W., Laird, J.G. Wilbanks, M.S., Rawat, A., Indest, K.J., Roe, B.A., Perkins, E.J., 2014. Coralzooxanthellae meta-transcriptomics reveals integrated response to pollutant stress. BMC Genomics 15, 591. https://doi.org/10.1186/1471-2164-15-591, 2014.

Gust, K.A., Stanley, J.K., Wilbanks, M.S., Mayo, M.L., Chappell, P., Jordan, S.M., Moores, L.C., Kennedy, A.J., Barker, N.D., 2017. The increased toxicity of UVdegraded nitroguanidine and IMX-101 to zebrafish larvae: evidence implicating oxidative stress. Aquat. Toxicol. 190, 228-245.

Gust, K.A., Lotufo, G.R., Stanley, J.K., Wilbanks, M.S., Chappell, P.S., Barker, N.D., 2018. Transcriptomics provides mechanistic indicators of mixture toxicology for IMX101 and IMX-104 formulations in fathead minnows (Pimephales promelas). Aquat. Toxicol. 23 (199), 138-151. https://doi.org/10.1016/j.aquatox.2018.03.019.

Haag, W.R., Spanggord, R., Mill, T., Podoll, R.T., Chour, T.-W., Tse, D.S., Harper, J., 1990. Aquatic environmental fate of nitroguanidine. Environ. Toxicol. Chem. 9, 1359-1367.

Halasz, A., Hawari, J., Perreault, N.N., 2018. New insights into the photochemical degradation of the insensitive munition formulation IMX-101 in water. Environ. Sci. Technol. 52 (2), 589-596.

Han, G.H., Hur, H.G., Kim, S.D., 2006. Ecotoxicological risk of pharmaceuticals from the wastewater treatment plants in Korea: occurrence and toxicity to Daphnia magna. Environ. Toxicol. Chem. 5, 265-271.

Johnson, L.R., Davenport, R., Balbach, H., Schaeffer, D.J., 1994. Phototoxicology. 3. Comparative toxicity of trinitrotoluene and aminodinitrotoluenes to Daphnia magna, Dugesia dorotocephala, and sheep erythrocytes. Ecotoxicol. Environ. Saf. 27, 34-49.

Kaplan, D.L., Cornell, J.H., Kaplan, A.M., 1982. Decomposition of Nitroguanidine. Environ. Sci. Technol 16, 488-492.

Kennedy, A.J., Laird, J.G., Lounds, C., Gong, P., Barker, N.D., Brasfield, S.M. Russell, A.L., Johnson, M.S., 2015. Inter- and intra-species chemical sensitivity: a case study using 2,4-dinitroanisole. Environ. Toxicol. Chem. 2, 402-411. https:// doi.org/10.1002/etc.2819.

Kennedy, A.J., Poda, A.R., Melby, M.L., Moores, L.C., Jordan, S.M., Gust, K.A., Bednar, A.J., 2017. Aquatic toxicity of photo-degraded insensitive munition 101 (IMX-101) constituents. Environ. Toxicol. Chem. 36, 2050-2057.

Krzmarzick, M.J., Khatiwada, R., Olivares, C.I., Abrell, L., Sierra-Alvarez, R., Chorover, J., Field, J.A., 2015. Biotransformation and degradation of the insensitive munitions compounds, 3-Nitro-1,2,4-triazol-5-one, by soil bacterial communities. Environ. Sci. Technol. 49, 5681-5688.

Laird, J.G., Kennedy, A.J., Melby, N., Lounds, C., Gong, P., 2015. Development of a chronic toxicity testing method for Daphnia pulex. ERDC/EL SR15-5, U.S. Army Research and Development Center, Vicksburg, MS. . http://acwc.sdp.sirsi.net/ client/en_US/default/index.assetbox.assetactionicon.view/1045449; jsessionid=7F6A7FE02293B7057DD17C3B8C76BF11.enterprise_15000?rm =\% E2\%80\%A2ENVIRONMENTAL011true.

Lee, K.E., Balas-Hummers, W.A., Di Stasio, A.R., Patel, C.H., Samuels, J., Roos, B.D., Fung, V., 2010. Qualification testing of the insensitive TNT replacement explosive IMX-101. In: Proceedings, 2010 Insensitive Munitions \& Energetic Materials Technology Symposium, pp. 1-13. Munich, Germany.

Li, Y., Hsieh, W.P., Mahmudov, R., Wei, X., Huang, C.P., 2013. Compined ultrasound and Fenton (US-Fenton) process for the treatment of ammunition wastewater. J. Hazard Mater. 244-245, 403-411.

Le Campion, L., Delaforge, M., Noel, J.P., Ouazzani, J., 1998. Metabolism of ${ }^{14} \mathrm{C}$ labelled 5-nitro-1,2,4-triazol-3-one (NTO): comparison between rat liver microsomes and bacterial metabolic pathways. J. Mol. Catal. B Enzym. 5, 395-402.

Le Campion, L., Giannotti, C., Ouazzani, J., 1999. Photocatalytic degradation of 5Nitro-1,2,4-triazol-3-one NTO in aqueous suspention of $\mathrm{TiO}_{2}$. Comparison with fenton oxidation. Chemosphere 38 (7), 1561-1570.

Lotufo, G.R., Stanley, J.K., Chappell, P., Melby, N.L., Wilbanks, M.S., Gust, K.A., 2018. Subchronic, chronic, lethal and sublethal toxicity of insensitive munitions mixture formulations relative to individual constituents in Hyalella azteca Chemosphere 210, 795-804, 10.1016/j.chemosphere.2018.07.049.

Mack, J., Bolton, J.R., 1999. Photochemistry of nitrite and nitrate in aqueous solution: a review. J. Photochem. Photobiol., A 128, 1-13.

Moores, L.C., Jones, S.J., George, G.W., Henderson, D.L., Schutt, T.C., 2019. Photo degradation kinetics of insensitive munitions consitutents nitroguanidine nitrotriazolone, and dinitroanisole in natural waters. J. Photochem. Photobiol., A. https://doi.org/10.1016/j.jphotochem.2019.112094 (in press).

Noss, C.I., Chyreck, R.H., 1984. Nitroguanidine Watewater Pollution Control Technology: Phase III. Treatment with Ultraviolet Radiation, Ozone, and Hydrogen Peroxide. US Army Medical Bioengineering Research and Development Laboratory, Fort Detrick, MD, pp. 1-28. Technical Report ADA139389. Sep 1983-Dec 1983.

Organisation of Economic Cooperation and Development (OECD), 2012. Test No. 211: Daphnia Magna Reproduction Test. OECD, Paris, France.

Pace, M.D., Holmes, B.S., 1983. Spin trapping of $\cdot \mathrm{NO}_{2}$ radicals produced by uv photolysis of RDX, HMX, and nitroguanidine. J. Magn. Reson. 52, 143-146.

Perreault, N.N., Halasz, A., Thiboutot, S., Ampleman, G., Hawari, J., 2013. Joint photomicrobial process for the degradation of the insensitive munition Nguanylurea-dinitramide (FOX-12). Environ. Sci. Technol. 47, 5193-5198, 2013.

Rao, B., Wang, W., Cai, Q., Anderson, T., Gu, B., 2013. Photochemical transformation of the insensitive munitions compound 2,4-dinitroanisole. Sci. Total Environ. 443, 692-699.

Ribeiro, E.N., Da Silva, F.T., De Paiva, T.C.B., 2012. Ecotoxicological evaluation of wastewater from 2,4,6-TNT production. J. Environ. Sci. Health, Part A. 47 (2), 184-191.

Russell, A.L., Seiter, J.M., Coleman, J.G., Winstead, B., Bednar, A.J., 2014. Analysis of munitions constituents in IMX formulations. Talanta 128, 524-530.

Scott, G., Crunkilton, R.L., 2009. Acute and chronic toxicity of nitrate to fathead minnows (Pimephales promelas), ceriodaphnia dubia, and Daphnia magna. Environ. Toxicol. Chem. 19, 2918-2922.

Spanggord, R.J., Chou, T.W., Mill, T., Haag, W., Lau, W., 1987. Environmental Fate of Nitroguanidine, Diethyleneglycol Dintrate, and Hexachloroethane Smoke. SRI International, pp. 1-67. Menlo Park, CA. Technical Report ADA200324. May 1986-Apr 1987.

Stanley, J.K., Lotufo, G.R., Biedenbach, J.M., Chappell, P., Gust, K.A., 2015. Toxicity of the conventional munitions constituents TNT and RDX relative to new insensitive munitions DNAN and NTO in Rana pipiens tadpoles. Environ. Toxicol. Chem. 34 (4), 873-878. https://doi.org/10.1002/etc.2890.

Swann, P.F., 1975. The toxicology of nitrate, nitrite and n-nitroso compounds. J. Sci. Food Agric. 26 (11), 1761-1770.

Taylor, S., Park, E., Bullion, K., Dontsova, K., 2015a. Dissolution of three insensitive munitions formulations. Chemosphere 119, 342-348.

Taylor, S., Bigl, S., Packer, B., 2015b. Condition of in situ unexploded ordnance. Sci. Total Environ. 505, 762-769.

Taylor, S., Walsh, M.E., Becher, J.B., Ringelberg, D.B., Mannes, P.Z., Gribble, G.W., 2017 Photo-degradation of 2,4-dinitroanisole (DNAN): an emerging munitions compound. Chemosphere 167, 193-203.

US Environmental Protection Agency, 2002. Methods for Measuring the Acute Toxicity of Effluents and Receiving Waters to Freshwater and Marine Organisms. EPA 821/R-02/012, 5th ed. Office of Water, Washington, DC.

van der Schalie, W.H., 1985. The Toxicity of Nitroguanidine and Photolyzed Nitroguanidine to Freshwater Aquatic Organisms. Army Medical Bioengineering Research and Development Lab, Fort Detrick, MD, pp. 1-35. Technical Report: ADA153045. Oct 1982-Apr 1984.

Warner, C.M., Gust, K.A., Stanley, J.K., Habib, T., Wilbanks, M.S., Garcia-Reyero, N., Perkins, E.J., 2012. A systems toxicology approach to elucidate the mechanisms involved in RDX species-specific sensitivity. Environ. Sci. Technol. 46, 7790-7798.

Williams, L.R., Eck, W.S., Johnson, M.S., 2014. Toxicology Assessment of IMX-101 Public Health Command. Toxicology Report No. S.0002744-14.

Xiang, F., Yang, W., Chen, Y., Yang, Z., 2010. Acute toxicity of nitrite and ammonia to Daphnia Similoides of different developmental stages: using the modified Gaussian model to describe, 84, 708-711. 


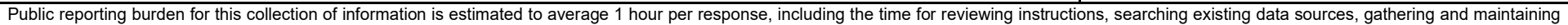

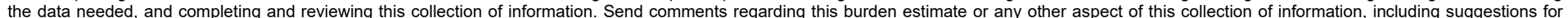

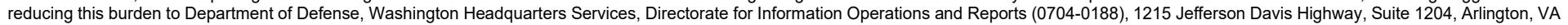

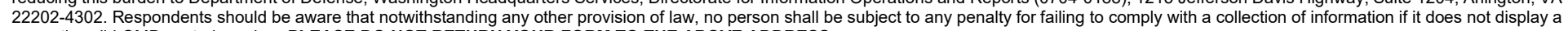
currently valid OMB control number. PLEASE DO NOT RETURN YOUR FORM TO THE ABOVE ADDRESS.
1. REPORT DATE (DD-MM-YYYY)
2. REPORT TYPE
September 2021
Final

4. TITLE AND SUBTITLE

Identifying Degradation Products Responsible for Increased Toxicity of UV-Degraded Insensitive Munitions

3. DATES COVERED (From - To)

5a. CONTRACT NUMBER

5b. GRANT NUMBER

5c. PROGRAM ELEMENT NUMBER

5d. PROJECT NUMBER

6. AUTHOR(S)

Lee C. Moores, Alan J. Kennedy, Lauren May, Shinita M. Jordan, Anthony J. Bednar, Stacy J. Jones, David L. Henderson, Luke Gurtowski, Kurt A. Gust

\section{PERFORMING ORGANIZATION NAME(S) AND ADDRESS(ES)}

Environmental Laboratory

U.S. Army Engineer Research and Development Center

3909 Halls Ferry Road

Vicksburg, MS 39180

HX5

212 Eglin Parkway SE

Ft. Walton Beach, FL 32548

9. SPONSORING / MONITORING AGENCY NAME(S) AND ADDRESS(ES)

U.S. Army Corps of Engineers

Washington, DC 20314

\section{DISTRIBUTION / AVAILABILITY STATEMENT}

Approved for public release; distribution is unlimited.

13. SUPPLEMENTARY NOTES

This article was originally published online in the journal Chemosphere on 24 September 2019.

The research was conducted under the USACE Environmental Quality and Technology Program by the ERDC.

\section{ABSTRACT}

Degradation of insensitive munitions (IMs) by ultraviolet (UV) light has become a concern following observations that some UVdegradation products have increased toxicity relative to parent compounds in aquatic organisms. This investigation focused on the Army's IM formulation, IMX101, composed of three IM constituents: 2,4-dinitroanisole (DNAN), 3-nitro-1,2,4-triazol-5-one (NTO), and nitroguanidine (NQ). The IM constituents and IMX101 were irradiated in a UV photo-reactor and then administered to Daphnia pulex in acute $(48 \mathrm{~h})$ exposures comparing toxicities relative to the parent materials. UV-degradation of DNAN had little effect on mortality whereas mortality for UV-degraded NTO and NQ increased by factors of 40.3 and 1240, making UV-degraded NQ the principle driver of toxicity when IMX101 is UV-degraded. Toxicity investigations for specific products formed during UVdegradation of NQ, confirmed greater toxicity than the parent NQ for degradation products. Summation of the individual toxic units for the complete set of individually measured UV-degradation products identified for NQ only accounted for $25 \%$ of the overall toxicity measured in the exposures to the UV-degraded NQ product mixture. Given the underestimation of toxicity using the sum toxic units for the individually measured UV-degradation products of NQ, we conclude that: (1) other unidentified NQ degradation products contributed principally to toxicity and/or (2) synergistic toxicological interactions occurred among the NQ degradation product mixture that exacerbated toxicity.

\section{SUBJECT TERMS}

Nitroguanidine, Cyanide, Nitrosoguanidine, Daphnia pulex, Toxicity, IMX-101

16. SECURITY CLASSIFICATION OF:

\section{a. REPORT}

Unclassified

\section{b. ABSTRACT}

Unclassified c. THIS PAGE

Unclassified
17. LIMITATION OF ABSTRACT

UU
18. NUMBER OF PAGES

13 19a. NAME OF RESPONSIBLE PERSON

19b. TELEPHONE NUMBER (include area code) 